\title{
Theatrical Storytelling From Page to Stage: An Applied Study in Writing and Performing Techniques
}

\author{
Gamal El-Sayed Hussein Mohamed Yakout \\ Alexandria University, Alexandria, Egypt
}

\begin{abstract}
Storytelling is an important performing art. Attracting theater practitioners and audiences are the main targets. Successful narrator communication is one of the biggest challenges even when theatres facilitate communication with scenery, lighting and costumes etc., as the performance depends primarily on the text and narrator for successful expression. This study views the most important techniques to create a well-made story at both text and performance levels. The researcher begins differentiating storytelling, imitation and characterization, as this understanding assists the objective of this study, which is to determine specific techniques to achieve successful communication with an audience. This research highlights elements which distort story structure; including immersion in narrative without incident description, identified as the most dangerous element due to description being essential to create suspense. ${ }^{1}$ Text condensation is also crucial. A good writer uses his pen more for deletion than addition. Repeated reading and deletion to condense the story to its optimal is vital. Also included are techniques for good text rhythm in addition to production of captivating beginnings. Further techniques to raise audience attention in text and event building, as well as to determine conflict and types, narrator language use and the structure of the diagnostic viewer, finally, mastering story ending techniques are provided. At performance level, this research provides techniques in creativity prologue, good story rhythm, body language and eye contact together with prop (object) use; all of which enable the narrator to capture and retain audience attention throughout. This research concludes with recommendations on how to achieve a good storytelling performance.
\end{abstract}

Keywords: storytelling, narrator and audience communication, successful storytelling performance, theatre techniques

\section{Introduction}

"Storytelling is frightening and exhilarating, because it involves a journey to the unknown" (Johnstone, 1999, p. 75), Therefore, the "professional storytellers, and their disciples have come to believe they are one big loving family. Storytelling is more than a profession, it is their religion. They are convinced that if everyone learned how to tell stories to communicate their genuine feelings, the world would be a better place" (Zipes, 2004, p. xiii).

Storytelling is a performing art attracting many theater practitioners in recent years. "The drama is a form of storytelling" (Davis, 2003, pp. 52-53) because it narrates a story live with actors performances and targets

\footnotetext{
* ATINER started to publish this conference papers series in 2012. It includes only the papers submitted for publication after they were presented at one of the conferences organized by our Institute every year. This paper has been peer reviewed by at least two academic members of ATINER.

Gamal El-Sayed Hussein Mohamed Yakout, Lecturer, Theater Department, Alexandria University.

${ }^{1}$ 6th International Conference on Visual and Performing Arts, 1-4 June 2015: Abstract Book 53.
} 
audiences. The success of a storyteller lies in effectively connecting with the audience and is a prime. In order to achieve this, two essential components must be present, which represent the essence of communication between the storyteller and audience, namely, the script of the story, and the performance itself.

The presence of theatrical script is incomplete unless performed live as opposed to a book were the story ends once it's written and read.

This research involves stories that are written to be performed either individually or in the full context of a storytelling performance, and this lead the writer to deal with the story as a preliminary stage of the performance, and not as a final literary product. The writer is committed to a set of technical standards that ensure creative quality. Without adherence to these standards, the result is a fragile story that does not achieve effective communication with the audience.

Indulgence with narration is a problem the writer faces within himself, in addition to other problems such as: including sound, images, and details, or failing to include elements of surprise, thrill and excitement. These important factors ensure the enduring capture of the audience's minds. The same elements of intrigue can be

applied at the second stage, which concerns techniques used to make a good story in terms of performance. In order to create and achieve an effectively communicated story, one must capture their minds by maintaining a good rhythm, a good opening and a clear ending.

This research begins with a review of story types according to their sources, and addresses the story presentation differing forms in theater. It then explores the most important differences between storytelling and characterization, followed by an illustrated and detailed account of the most important techniques which ensure a good story structure, and good performance techniques. The research concludes with the findings and recommendations.

\section{Story Sources}

"Theater starts from the idea of working on the embodiment of the incident" (Korome, 2004, p. 49), in the case of theatrical storytelling its source as an incident which the storyteller relates to the audience. The theatrical story sources are identified as follows:

(1) Living Storyteller -Real Experience.

(2) Living Others Realistic Experience:

- Transmitted Stories;

- Fictional Story;

- Abstract Story;

- Story Inspired from an Object;

- Improvised Story.

\section{Storytelling and Characterization}

The storyteller communicates to the audience with their true personality to narrate a past incident which is now ended, however in the delusive theater, the actor enters into the character that they are performing, in the present. The most important differences between storytelling and delusive characterization are in Table 1 .

So what is the significant requirement of adding characterized scenes into the body of narrative story?

In answer, the characterized scenes are those written in dialogue between the characters within the story. The story writer resorts to dialogue scenes to break monotony which may arise from the continued use of 
narrative techniques, leading to distraction of the audience. Dialogue scenes achieve diversity in sound, its layers, and sources, and achieve varied tempos to accomplish vital rhythm.

Dialogue scenes can be characterized to help the audience clearly identify with accents in speech, revealing the nature of the social environments and cultural backgrounds. As for the storyteller, the dialogue scenes revitalize them, renewing energy and enabling them to excel in performance. The audience senses this enthusiasm and identifies with the story events, raising eagerness to know what happens next.

This characterization of dialogue cannot be performed the same way as delusive performances, because the expectations of the audience are based on the storyteller narrating an event from the past. This is so even if the event occurred in the present and the main character is the storyteller. Consequently, the storyteller employs the technique of personifying multiple characters within the story to achieve the "audience captivation" objectives.

For these reasons, performing dialogue scenes are not fully performed to a delusive degree, because the audience would not be convinced. There would also be a large discrepancy between the reality of the story, and the performance and characterization approach. Characterization should not appear as a foreign element to the story especially as characterization and practical experience has proven the accepted percentage of characterization in dialogue scenes inside the narrative story should not exceed $25 \%$. To clarify this in more detail, we present below an anonymous folk story.

Table 1

Differentiation of Storytelling and Delisive Characterization

\begin{tabular}{|l|l|l|}
\hline Item & Delusive characterization & Storytelling \\
\hline Act & Delusive & Non-Delusive \\
\hline Actor & $\begin{array}{l}\text { Present himself/herself as the theatrical } \\
\text { character, and totally separates } \\
\text { himself/herself from his/her real character. }\end{array}$ & $\begin{array}{l}\text { Presents himself/herself as the real } \\
\text { character, with no separation of his/her real } \\
\text { character. }\end{array}$ \\
\hline Events Time & Now & In the past \\
\hline Events Place & Here & Here or elsewhere. \\
\hline Characterization & $100 \%$ & Not exceeding 25\% in the case of necessity. \\
\hline Performer of a Number of Characters & Performer of every character & Performer of all characters. \\
\hline
\end{tabular}

\section{The Carpenter Story and the Sea Fairy}

There was an old carpenter working on a river bank, his capital was his hammer and saw. One day, while he was engaged in sawing large wooden blocks, his saw slipped from his hands and fell into the river. As he was crying, a Sea Fairy came to him and asked him:

-What makes you cry, dear old man?

-My saw, fell in the river, and it is the means of my living.

-Do not worry ... I'll bring it to you immediately.

The Fairy dived deep into the river, and shortly after, she returned with a gold saw in her hand and gave to the carpenter.

-Take ye old man. Here is your saw.

-But this is not my saw.

The Fairy was impressed by the man's honesty as he did not accept the forbidden gold saw. She then immersed in the river again and came out with a silver saw, which she gave to the man. 
-Ye old man here take this. This is your saw.

-But this is not my saw.

So again the fairy immersed in the river depth and came out with a Bronze saw giving it to the man:

-Ye old man here take this. This is your saw.

-But this is not my saw.

The fairy realized the honesty of the man and then she dived in the river and returned with the his saw, which the old carpenter was happy to see.

-Yes, this is my saw. Praise be to God.

As a reward for the poor man's honesty, the Fairy gave the Gold, the Silver, and the Bronze saws to the old man. The old carpenter went to his wife to tell her the good news, and they decided to celebrate at the river bank. Whilst there, his wife's feet slipped and she fell into the river. As the carpenter sat weeping for his wife, the Fairy came to him and asked:

-Why are you crying again?

-My wife fell into the river.

-Do not cry ... I will bring her to you.

The Fairy dived and came out with Marilyn Monroe and she asked him:

-Is this she?

-Yes, it is my wife.

The Fairy looked crossly at him.

-Why are you lying, deceiver?

-I did not lie ... I was afraid to say no, because you would dive again and bring Julia Roberts, and if I said no again, you would dive again and bring Nicole Kidman, and if I said no again, you would dive again and bring me my real wife. If I then say yes this is my wife, you would give me all three women as a reward, but I am an old man and I would not be capable for them all, so I was content with just Marilyn Monroe and to let my wife be happy with the crocodiles which would eat her in the Nile.

\section{Story Textual Structure Techniques}

Story has multiple forms on the text level which can be separated as follows:

- A separate written story.

- A story in the context of complete storytelling performance including anecdotes linked with lyrical or musical breaks.

- A story in the context of a normal dramatic performance (play) where the narrator - or more - delivers the story - or stories.

Whatever the nature of the text, the story has specifications which must be taken into account to ensure the quality level of performance in order to achieve the aims of the story.

\section{Story Elements on the Text Level}

Good story text includes a set of elements that can be identified as follows: 


\section{The Idea}

A good story text has an intellectual value and often this is directly related to the target audience. The story ideas often center on humanitarian, social, economic or political aspects, and because the story is usually short, it is characterized simply and clearly. The value derived by the audience in the sarcasm that shook the old man's status as a result of his violation confirms that change is not achieved through the cleansing logic, as is the case in tragedy, but also that the logic of change can be produced with comedy.

\section{Good Opening}

The story opening is the most critical in its structure. A good story is able to capture the audience's minds from the first instance, using techniques to elicit surprise and excitement on top of various other techniques, such as in the script with an opening of a point of attack, or with a question, temptation or problem requiring a solution for active audience captivation and participation, although there are risks when involving the audience, because their reactions may not be time efficient and stray from the story line. This technique, therefore, requires great skill and experience.

\section{Plot}

The story plot relates to the sequence of events within the story so each event leads to the following one smoothly. According to the law of cause and effect, the best story is one where if a part of it was deleted, it either collapses or is turned into an all-new event. Access to a good coherent plot in event structure is one that contains the elements of surprise and excitement. The story events we presented include a range of sequences including:

(1) An old carpenter working on a river (Introduction to view the topic (Exposition)).

(2) The old man's saw fell in the river (point of attack).

(3) The old man cries due to his inability to get the saw (conflict with destiny).

(4) The emergence of the Sea Fairy offering to assist (a surprise for the audience and hope for a solution)

This sequence captivates the audience. This type of communication is the objective and should result in enjoyment for the audience.

\section{Dramatic Structure}

Because the story mostly includes one dramatic theme, the structure is often a traditional construction, including a beginning, middle and end. The beginning includes the subject exposition and introduces the basic characters. The performance must be characterized concisely, because excessive elaboration would affect the story rhythm. In addition, insufficient information affects understanding of the plot. The balance between being concise and elaborating on detail is determined by the rhythm of the opening. Within the center of the story, any conflict must be escalated between the struggling parties. This should lead to the flare that produces a state of dramatic tension to surprise and captivate the audience. The last stage in the dramatic line includes the story ending and must be characterized thoroughly and decisively.

\section{Conflict}

"The conflict is either internal or external with the community or with other people as their interests' conflict with the hero's interests" (Bown \& Gawthorope, 2007, p. 82), therefore, conflict increases audience anticipation. Escalating conflict is appropriate where the action and reaction are equal, because it stimulates and drives the audience to want to witness the end result. 


\section{Condensation}

There are many techniques we can use to achieve an intensive story structure in its writing; however, the most important things are those that could distort the story structure. The narration is based on a singular theme and sometimes includes a detailed description. Therefore, over obsession in the narrative by not focusing on an event as much as it focuses on a description is a dangerous element. This preoccupation could demolish communication. Condensation is one of the most important methods the writer must use to achieve a good story. A good writer is one who uses his pen more for deletions than for additions. After deleting, read it again, because inevitably the writer will find further deletions can be made.

\section{Rhythm}

The rhythm - in relation to story text-is one of the essential pillars that lead to creating a good story. Good rhythm is achieved by reaching image and sound diversity in relation to the story, which can be achieved by demonstrating diversity when representing the story characters and describing the events. The use of determined pauses with high pitch and low tone vocal points, in addition to determining the characters locations on stage and method of body performance is vital. The writer must therefore plan for vocal tone and visual variations to produce good rhythm and captivate the audience during the performance.

\section{Events}

The events within the story are an important factor for success. A good event provokes the audience's amazement and verifies their involvement. The writer has to obtain scripting and technical means to attract audience attention, with elements of surprise, suspense, shock and humour within the space between the story and narration.

\section{Characters}

The characters carry the story concepts and events. A good story contains only the characters needed. Excess characters distract an audience from the plot. The story we presented had a carpenter, his wife and a Fairy, no more characters are needed to convey the idea. Furthermore, deletion of one of these characters means the destruction of the story, and in spite of the wife's absence, this exclusion benefited the text structure in rhythm because it gave contrast and diversity without affecting the plot.

\section{Language}

Since the story is a narrative art dependent on speech, the language has a major impact on the story success. Word interpretations vary depending with environment and culture. The story writer should therefore be committed to an easy flowing style and choose words appropriate to the moral composition and nature of the audience. It is not appropriate, for example, that the writer chooses words which alienate an audience. The writer must also avoid stylistic complicity and arrogance by using difficult terms. Sometimes - especially in the old stories - the writer resorts to the use of ancient words to imbue the story with a local tint which is fine, but the excessive use of alternative words with the same meanings results in audience boredom.

In the case of the story dialogue, the writer must use appropriate language for each character, especially if the story is fictional and has no realistic reference. It is not appropriate; for example, for the writer to put complex words on the simple carpenter's lips.

\section{Structure of Dialogue Scenes Included in the Story Body}

"Dialogue is the preliminary tool for the playwright to communicate with the audience. Many writers 
believe that the main reason for their love of the theater is their love of and talent in writing dialogue" (Neipris, 2005 , p. 43). Thus arises the importance of dialogue scenes to develop the audience's imagination enabling visualization of the ongoing events with diversity, and also as the story changes from narrative, to mixed narrative and dialogue. This improves rhythm and audience imagination with the characters and makes the events and characters more realistic.

\section{Finally}

The conclusion of the story is one of the main areas which gives the story a qualifying certificate as either a good or bad. A good ending is decisive and conclusive with a clear interpretation. Doubt should not be left with the audience, because multiple ending possibilities confuse the audience. A fully resolved ending is achieved by choosing a clear and powerful combination of words to help the performer orate the conclusion decisively.

\section{Techniques of Story Performing}

The traditional theater has many components which facilitate the communication process such as lighting, music, songs, costumes and make-up, which help to attract the audience during the performance. Theatrical storytelling is capable of being a self-contained, yet integrated theatrical performance, even if it lacks all other performance elements except for the storyteller and audience, because "There is no existence of a real theater without audience" (Yousefi, 2013, p. 100), which means "the non-interaction of audience with the theatrical process is a denial of the whole process" (Sallam, 2004, p. 19). Even if supporting elements are used to assist; the success of communication between performance and audience relies on the quality of story building within the text as well as performance. The "art of acting cannot be learned, because the actor is born with the ability to act; the technology simply enables the actor to express his talent - and this technology can be learned" (Bartow, 2008, p. xv), so storytelling alone cannot create a skillful storyteller from someone lacking this talent, however, the storyteller can learn a number of techniques to capitalize on the talent they do have. The following techniques can achieve a minimum guarantee of a well-made story:

\section{Good Opening}

A good opening involves the storyteller's ability to provide a relationship between the sound layer, its volume, and ability to split sentences including specific stops for each word or sentence in a way that captivates the audience, and openings with a low voice, stuttering and uncontrolled pauses result in audience withdrawal.

The storyteller's body stance is vital to impose control over the audience along with silences, which are of great importance in this matter. Advices given to the actor is that "even when another actor speaks, the pulse and your actions must never stop" (Chubbuck, 2004, p. 97). The primary goal of the storyteller is to capture with full capacity and strength the audience's minds from the outset.

\section{Language}

Ibn Jinae defines the concept of language as "voices expressed by each person for their own purposes, in that they are varied in significance and they are different depending on its users" (Abu-Hassan, 2005, p. 21). Thus, the story must be presented in the language spoken by the receiving audience, and where the language between the storyteller and the audience differs, they must to resort to a third language to intermediate. This was done by the researcher when he conducted two consecutive training sessions at the International Festival of Theater Industry, organized by Change Theater in Athens in 2013 and 2014, where stories were presented in 
English. Using a different language is a big risk, because if the storyteller lacks complete mastery of the language, it has a range of negative issues including:

- Using inaccurate vocabulary to express a word or position. The storyteller may have to cut the story to explain to the audience, but this must be cleverly done in context with the story.

- An inability to vocalize the dramatic situation that expresses the ideas of the story, which confuses the storyteller and audiences. This problem cannot be solved, because vocabulary represents the backbone of the story.

A negative impact on the storyteller's concentration as a result of distractions and attempts to find the meanings. The same applies with different dialects. Presenting a written story with a northern accent to southern people in a mixed dialect community, would impact on audience understanding especially when there are drastic differences in interpretation.

\section{Set the Story General Rhythm}

In spite of "the clarity of the image, the story rhythm is emphasized in the spectator's mind through repetition of one movement or one subject" (al-Azab, 1989, p. 31), but unjustified repetition is the enemy of rhythm, because the essence of good rhythm is diversity. Therefore, the rhythm of the story is determined through the storyteller's ability in visual and vocal diversity, and where the scene in storytelling performances often includes just the storyteller and a fixed background, the greatest burden lies with the storyteller's ability with acoustic variations. Characterization is also an important area which improves rhythm, as it gives a greater chance of audience familiarity, in addition to the cold to hot or hot to cold strategies-meaning reaching the peak of hype and then a state of silence, or the opposite-is one of the most important strategies used to improve rhythm in performance. It is a misconception that loud or fast performances are a magical means to grab the audience's attention. This belief is due to confusion between rhythm and tempo. Tempo is in relation to time, which differs from rhythm, which is the essence of the act in relation to a range of tempos. In either case, stability of sound or image for long periods causes bad rhythm. Consistent and lengthy fixed audio levels - no matter what volume-will definitely lead to audience withdrawal, therefore, the combination of differing of sounds and images must be used to create diversity and improve performance rhythm.

\section{Dramatic Dissolve}

Dramatic dissolve is movement from one area to another within the story, which is one of the storyteller's weapons used to bring diversity. The method of movement from one scene to another is a major challenge because it can either attract the audience's attention or repel them from the performance.

Dramatic dissolve is of two types:

- Soft dissolve; is the gradual transition from one situation to another in the story.

- Sharp transition, is dissolve achieved suddenly.

The choice of transition form, and thus the quality of the dissolve, is one of the most important techniques that the storyteller should pay attention to, because this transition could maintain the link with the audience or dismiss them from the story, because the transition type directly affects the rhythm of the story.

\section{Use of Objects Related to the Story}

Sometimes objects are closely linked to the story. Sometimes sensory emotions are not increased by the story except when the eye sees this object, which requires story teller's scrutiny in timing when showing the object. In the story (my friend) performed by an old Greek woman who suffered skin cancer, the women 
presented her story, which is closely related to an ointment tube that she cannot go without because she needs to apply it to her body from time to time, especially at the times of pain. Therefore, showing the ointment before the audience realizes its importance would distract their minds as they begin to question what this is for, and thus lose focus on the story. However, having the ointment tube present in the ladies hands at the appropriate time would improve the audience's interaction with the story events.

\section{Body Language}

The body has rhythm like words; its motionlessness separates the audience from the story, and exaggeration in movement causes audience dispersion. However, rational body movements bring balance and maintain the audience's link to the story. The Storyteller should also distribute body position among audience as equally as possible.

\section{Eye Contact}

Eye contact with the audience must be maintained with fair distribution, and gives the audience a sense of worth, contributing to their relationship with the story, whilst looking at non-specific points, would distract the audience.

\section{Helping Factors}

Storytelling performances are almost always abstract, with no theatrical image elements and with a storyteller standing — or sitting - lonely and isolated in the face of the audience. This is because "There is truth in the saying that a picture is worth a thousand words" (Converse, 1995, p. 210), it is for the storyteller to make up for the absence of images by adding display theatrical elements such as songs to help counteract this stagnancy and to achieve a state the audience connection with performance. Adding a number of songs would achieve a unique theatrical status because "the use of the song strengthens the actor's—or storyteller's — sense of living the situation" (Mitter, 2007, p. 85) and this deepens the distinct emotional state among the audience. Also, some simple illuminations must be done in order to achieve a surprise.

\section{Characterization}

Characterization of dialogue represents one of the areas to enable the storyteller to achieve a characterized case. The Storyteller comes out of the monotone narrative into character to achieve audio diversity provoking the audience's attention. However, indulging in the characterization in a way which transmits the story to traditional analog scenes is a huge mistake and does not achieve the goal of amazement in illusion. The storyteller should come out of character from time to time to achieve the lasting divergence between him and the characters that he is embodying. The storyteller should realize that characterization is not the aim of achieving illusion, but to achieve variety.

\section{End}

The end of the story is what remains in the memory after the audience leaves the venue, so it must be a decisive end of performance. The "actor is free in determining the completion, but they should prevent the destruction of the true ending" (Cole \& Chinoy, 1970, p. 271). In general, there should not be an anti-climax because this damages the story and negatively affects the audience.

\section{Findings and Recommendations}

Theatrical storytelling is one of the arts that sticks directly to the concept of intimacy. It is a very private 
situation assembled by the story teller and the audience craving to hear it. Therefore, the story should be important to this audience. It should discuss a relevant problem, be in their own language, and touch the audience's values containing the feelings and emotions that interact with the audience's conscience and passion. The story characters must come alive and stem from the audience's reality. As the story begins, it should raise audience attention, and push them into a rising conflict with gradual movements in which the action is equal to the reaction, and which complicates events and excites the audience to follow. The story should include a range of dialogue to identify discrepancies between the story characters and helps to achieve a state of audio and visual diversity. Finally the story must end with a clear interpretation and not fall into the multiple endings trap.

As for the performance, the storyteller should be attributed with presence, agility, beauty and a sedate sound; have the ability to excite the audience from the outset, both with the text and body movement, which express plainly the ideas posed by the words. Fair distribution of eye contact with the audience must be given, and finally the end has to be decisive with a clear interpretation.

The researcher recommends that more storytelling awareness needs to be published through the expansion of studies and research and to pave the way to access a more glowing story. The researcher recommends the expansion of training workshops to contribute to the training of a greater number of youth actors in the art of storytelling, and to form volunteer groups of artists go to small villages and cities collecting traditional stories from the local residents in order to preserve them. It would be preferable for the owners of the stories to perform them in a theatre, and for them to personally document them in order to benefit from the original nature of those people and to capture their unique communities thus retaining their heritage, particularly in communities with little media attention.

Finally, the researcher recommends organizing a group of theatrical storytelling festivals to include storytellers from different countries to achieve an artistic and cultural connection and an introduction to the customs and traditions of different nations and to encourage dialogue between civilizations.

\section{References}

Abu-Hassan, H. (2005). Semiotics theater, fulfillment house to a minimum printing and publishing. Alexandria.

al-Azab, F. (1989). Substantive elements of the motor expression, arts and printing equipment. Alexandria.

Bartow, A. (2008). Acting techniques. London: Nick Hern Book Limited.

Bown, L., \& Gawthorope, A. (2007). Teach yourself writing a play. UK: McGraw-Hill.

Chubbuck, I. (2004). The power of actor, the Chubbuck technique. London: Penguin Books Ltd.

Cole, T., \& Chinoy, H. K. (1970). Actors on acting. New York: Three Rivers Press.

Converse, T. J. (1995). Directing for the sage-A workshop guide of 42 creative training exercises and projects. USA: Meriwether Publishing Ltd.

Davis, R. (2003). Writing dialogue for scripts. London, UK: A\&C black.

Johnstone, K. (1999). Impro for storytellers. London: Faber and Faber Ltd.

Korome, A. (2004). Theatrical discourse, studies on stage, audience and laughter. Sharjah: Department of Culture and Information.

Mitter, S. (2007). Systems of Rehearsal, Stanislavsky, Brecht, Grotowski, and Brook. New York: Routledge Ltd.

Neipris, J. (2005). To be a playwright. New York: Routledge.

Sallam, A. H. (2004). Actor and theatrical philosophy laboratories, fulfillment house to a minimum printing and publishing. Alexandria.

Yousefi, H. (2013). Dramatizing of metaphor to the letter. The Department of Culture and Information, Sharjah, United Arab Emirates.

Zipes, J. (2004). Speaking out, storytelling and creative drama for children. New York \& London: Routledge. 